\title{
DEUTSCHE KUNST
}

\section{DAS MÜNSTER ZU AACHEN}

\author{
E in $F$ ührer \\ von \\ Paul Clemen
}

\author{
BERLIN W 8 \\ DEUTSCHER KUNSTVERLAG
}

1922 
Tafel 1-3 nach Aufnahmen der Staatl. Bildstelle, Tafel 4-7 u. 9 nach Aufnahmen, die vom Denkmälerarchiv der Rheinprovinz freundlichst zur Verfügung gestellt wurden, Tafel 8 nach Aufnahme von Dr. Franz Stoedtner. Die Bildstelle besitzt zahlreiche neuere Aufnahmen der Münsterarchitektur, die als photograph. Orig.-Abzüge, im Format $30 \times 40 \mathrm{~cm}$, als Vergrößerungen und als Diapositive durch den Deutschen Kunstverlag, Berlin W 8, Wilhelmstraße 69 , bezogen werden können. 


\section{INHALTS-ÜBERSICHT}

Einleitung . . . . . . . . . . . . . . . . . 5

Geschichte des Bauwerks . . . . . . . . . . . 8

Der Karolingerbau . . . . . . . . . . . . . . 13

Spätere Anbauten . . . . . . . . . . . . . . . 19

Ausstattung des Oktogons . . . . . . . . . . . 22

Die Schatzkammer . . . . . . . . . . . . . . 29

Das Münstermuseum . . . . . . . . . . . . . 37

Bibliographie . . . . . . . . . . . . . . . . 38

\section{VERZEICHNIS DER ABBILDUNGEN}

A. Auf Tafeln:

Oesamtansicht von Nordwesten . . . . . . . . . 1

Gesamtansicht von Südwesten . . . . . . . . . . 2

Blick in das Oktogon nach Osten (vor der Restaurierung) 3

Der Krönungsstuhl auf dem Hochmünster . . . . . 4

Zwei der Bronzegitter in den Öffnungen des Hochmünsters 5

Der Ambo Kaiser Heinrichs II. . . . . . . . . . 6

Die Pala d'oro auf dem Hochaltar . . . . . . . . 7

Der Karlsschrein. Schmalseite: Muttergottes zwischen

Gabriel und Michael . . . . . . . . . . . . 8

Der Marienschrein. Langseite: Karl d. Gr. und 6 Apostel 9

B. Im Text:

Rekonstruktion des karolingischen Baues:

Westansicht . . . . . . . . . . . . . . 14

GrundriB . . . . . . . . . . . . . . 15

Schnitt Ost-West . . . . . . . . . . . . . 16

Nordansicht. Zustand des Jahres 1520 . Zeichnung von

Albrecht Dürer . . . . . . . . . . . . 21 
